\title{
Isolinha erosiva máxima pelo método da krigagem na bacia hidrográfica do rio Paraíba, Brasil
}

\author{
Maximum erosive isoline by the krigage method in the Paraíba river \\ hydrographic basin, Brazil
}

\section{Isolina erosiva máxima por el método krigage en la cuenca hidrográfica del río Paraíba, Brasil}

Recebido: 04/05/2020 | Revisado: 11/05/2020 | Aceito: 13/05/2020 | Publicado: 22/05/2020

Manoel Viera de França

ORCID: https://orcid.org/0000-0003-4973-9327

Universidade Federal Rural de Pernambuco, Brasil

E-mail: manoelvieira.ufrpe@gmail.com

Raimundo Mainar de Medeiros

ORCID: http://orcid.org/0000-0003-3455-9876

Universidade Federal Rural de Pernambuco, Brasil

E-mail: mainarmedeiros@gmail.com

Wagner Rodolfo de Araújo

ORCID: https://orcid.org/0000-0001-7203-0338

Universidade Federal Rural de Pernambuco, Brasil

E-mail: wagneraraujops@gmail.com

\section{Resumo}

A erosividade pluvial divulga a capacidade pluviométrica de uma região de gerar erosão. Objetiva-se estudar a variabilidade geoespacionalizada gerando cartas do índice da erosividade da pluviometrica mensal e anual considerando a equação da perda do solo, do tempo de retorno erosivo, probabilidade e classificação erosiva além do coeficiente pluvial da bacia hidrográfica do rio Paraíba. Utilizou-se dos dados mensais e anuais de chuva do período de 1962-2018. A pesquisa quantitastiva realizada pelos dados pluviais. A utilização dos dados foi procedida de análise no tocante ao preenchimento de falhas, consistência, homogeneização. Na estimativa do índice de erosividade pluvial, aplicou-se a metodologia sugerida por Wischmeier e utilizando-se 
da equação simples de Bertoni. Sabe-se que os problemas ambientais transcorridos em determinada área interferem em toda a bacia causando impactos diretos de assoreamento e de degradação. Existe a necessidade do planejamento prévio de terrenos para implantação de pomares e de projetos agrícolas frutíferos, para que não ocorra o deslocamento de terra, amparado num monitoramento das mudanças que ocorrem no solo, em regiões de encosta, considerando-se as curvas de níveis do terreno. As áreas agricultáveis e seu entorno localizam-se ao longo de todo seu território tendo, suas regiões climáticas com diferentes potenciais erosivos. Logo, o conhecimento deste potencial será de enorme valor para escolha de práticas de manejo do solo visando controlar o seu processo erosivo. A concretização deste estudo vem a contribuir para políticas de planejamento e gestão regional ou local, onde, contribuirá como subsidio a novos desenvolvimentos de estudos.

Palavras-chaves: Flutuações pluviais; Mudanças climáticas: Solos; Cobertura vegetal.

\begin{abstract}
Rain erosivity discloses the rainfall capacity of a region to generate erosion. The objective is to study the geospatialized variability by generating charts of the monthly and annual rainfall erosivity index considering the equation of soil loss, erosion return time, probability and erosive classification in addition to the rainfall coefficient of the Paraíba River hydrographic basin. Monthly and annual rainfall data for the period 1962-2018 were used. Quantitative research conducted by rainfall data. The use of data was proceeded from analysis with regard to filling in gaps, consistency, homogenization. To estimate the rainfall erosivity index, the methodology suggested by Wischmeier was applied and using Bertoni's simple equation. It is known that the environmental problems experienced in a certain area interfere in the entire basin, causing direct impacts of silting and degradation. There is a need for prior planning of land for the implantation of orchards and fruitful agricultural projects, so that land displacement does not occur, supported by monitoring the changes that occur in the soil, in hillside regions, considering the level curves of the ground. The arable areas and their surroundings are located throughout its territory, having its climatic regions with different erosive potentials. Therefore, knowledge of this potential will be of enormous value in choosing soil management practices in order to control its erosion process. The completion of this study comes to contribute to regional or local planning and management policies, where it will contribute as a subsidy to new study developments.
\end{abstract}

Keywords: Rain fluctuations; Climate change; Soils; Vegetation cover.

\title{
Resumen
}


La erosividad de la lluvia revela la capacidad de lluvia de una región para generar erosión. El objetivo es estudiar la variabilidad geoespacializada mediante la generación de gráficos del índice de erosividad por lluvia mensual y anual considerando la ecuación de pérdida de suelo, tiempo de retorno de la erosión, probabilidad y clasificación erosiva, además del coeficiente de lluvia de la cuenca hidrográfica del río Paraíba. Se utilizaron datos de precipitaciones mensuales y anuales para el período 1962-2018. Investigación cuantitativa realizada por datos de lluvia. El uso de los datos se realizó a partir del análisis con respecto al relleno de huecos, consistencia, homogeneización. Para estimar el índice de erosividad de la lluvia, se aplicó la metodología sugerida por Wischmeier y se usó la ecuación simple de Bertoni. Se sabe que los problemas ambientales experimentados en un área determinada interfieren en toda la cuenca, causando impactos directos de sedimentación y degradación. Existe la necesidad de una planificación previa de la tierra para la implantación de huertos y proyectos agrícolas fructíferos, de modo que no ocurra el desplazamiento de la tierra, respaldado por el monitoreo de los cambios que ocurren en el suelo, en las regiones de laderas, considerando las curvas de nivel de la terreno. Las áreas cultivables y sus alrededores están ubicadas en todo su territorio, teniendo sus regiones climáticas con diferentes potenciales erosivos. Por lo tanto, el conocimiento de este potencial será de enorme valor al elegir las prácticas de manejo del suelo para controlar su proceso de erosión. La finalización de este estudio contribuye a las políticas regionales o locales de planificación y gestión, donde contribuirá como subsidio a los nuevos desarrollos del estudio.

Palabras clave: Fluctuaciones de lluvia; Cambio climático; Suelos; Cubierta vegetal.

\section{Introdução}

O monitoramento dos períodos chuvosos e secos e da variabilidade espaço temporal da precipitação é essencial para a gestão de recursos hídricos em áreas semiáridas. Devido às variabilidades na precipitação pluvial em função de diversos fatores é imprescindível um melhor conhecimento e interpretação das escalas da variabilidade pluviométricas que podem ser efetuadas por meio de índices segundo Alves \& Azevedo (2013).

Pereira, Angelocci \& Sentelhas (2012) afirmaram que a precipitação é a única fonte de suprimento d'água no semiárido nordestino, que ao escoar superficialmente é barrada em açudes, sendo usada para abastecimento público ou privado ou captada e armazenada em cisternas, para fins potáveis. 
Ataíde \& Furtado (2014) explicam que as variáveis meteorológicas analisadas umas com as outras são fontes de dados para possíveis explicações de variações climatológicas que ocorrem ou podem acontecer, e que pode influenciar a outra variável.

A potencialidade erosiva pluvial, entre vários meios de aplicações, possibilita dimensionar e melhora as composições de preservação do solo, assim como, estimar a produção de sedimentos de uma bacia hidrográfica, o qual é um dado bastante relevante no gerenciamento das soluções hídricos e na predição de impactos ambientais.

Pires \& Souza. (2013) afirmaram que a erosão é aferida como um método de origem natural com a finalidade de desenvolvimento da paisagem e preservação do solo. Os conflitos ocasionados pela erosão hídrica são: o enfraquecimento do solo devido à avaria de nutrientes e matéria orgânica, obstrução e contaminação dos corpos d'água pela condução de fertilizantes, agrotóxicos e lixos toxicos, causando mudanças diretas na fauna e flora conforme Bertoni et al. (2012) e Pires \& Souza. (2013). Gonçalves, Sampaio, Jesus \& Leão. (2015) demostraram que os riscos erosivos ou de oscilações de massa associado à geologia do Estado de Minas Gerais estão relacionados à porosidade, que interfere na quantidade do deflúvio acima da camada rochosa, à deformação tectônica e à presença de zonas de cisalhamento ou com intensidade das fraturas.

A erosão pluvial é uma das causas da deterioração do solo no Globo, com perdas elevadíssimas e com as taxas naturais de reposição, Needelman, (2013). No Brasil, a ponderação dos processos erosivos, com a ocupação e o uso inadequado do solo pelo homem, vem ocasionando assoreamento, transportando sementes, adubos e agrotóxicos para os lençóis d'água e os oceanos (Andrade, Freitas \& Landers (2010). As decorrências são dano de produtividade, avanço das fronteiras agrícolas, assoreamento e contaminação dos corpos hídricos, ocasionando prejuízos à biodiversidade e meio ambiente. Segundo afirmaram os autores acima citados, o planejamento das atividades agrícolas e pecuárias, contemplando as vulnerabilidades do ambiente e as potencialidades de uso, é imprescindível para minimizar sua degradação.

A região Nordeste do Brasil (NEB) apresenta alta variabilidade no clima, abrangendo desde regiões semiáridas, com precipitação anual acumulada inferior a $500 \mathrm{~mm}$, até climas chuvosos nas áreas costeiras, que apresentam precipitação anual superior a $1500 \mathrm{~mm}$, caracterizam-se também pelos processos de escoamento e erosão dos solos, e pelo alto potencial para evaporação da água em função da enorme disponibilidade de energia solar e altas temperaturas durante todo o ano (Oliveira, Silva \& Lima 2014; Souza, Alves \& Nobre., 1998). Os regimes de chuvas se apresentam de forma heterogênea tanto na escala espacial 
quanto nas escalas de tempo. Segundo o último relatório do Intergovernamental Painel on Climate Change (IPCC), o NEB é uma região altamente susceptível às mudanças climáticas, além de ser uma região sujeita à ocorrência de eventos de precipitação intensa; contudo ainda existem poucos estudos sobre a climatologia destes episódios na região.

Os processos erosivos superficiais de partículas do solo são causados pelas ações do vento e/ou d'água, ocasionando e/ou gerando erosões eólicas ou hídricas. A erosão hídrica é a mais importante e preocupante devido a variabilidade do clima tropical Bertoni et al. (2012).

Medeiros, Matos, Silva \& Saboya, (2015) utilizaram dados pluviais e de temperatura média do ar estimados pelo Software Estima_T para o período de 1912-2014. Elaborou cenário otimista e pessimista e calcularam o balanço hídrico climatológico para seis regiões homogêneas do Estado da Paraíba seguido do cálculo da erosividade. Os índices evaporativos exibiram aumentos nas regiões para os três cenários; os índices evaporados sofreram reduções para os cenários estudados; as deficiências e os excedentes hídricos apresentam oscilações de aumentos e redução nos seus valores verificou-se ainda diminuições da erosividade em todas as regiões de estudo.

$\mathrm{O}$ fator $\mathrm{R}$ da equação de perdas de solo simula o índice erosivo pluviais de uma dada região, tomado como base períodos de 20 a 30 anos de dados de chuvas. O fator R permite a avaliação do potencial erosivo das precipitações de determinado local, sendo possível conhecer a capacidade e o potencial da chuva em causar erosão no solo (Menezes \& Leite 2011). Para obtenção do fator R, é necessário determinar o índice de erosividade $\mathrm{EI}_{30}$, que representa o produto da energia cinética total da chuva pela sua intensidade máxima com duração de 30 minutos (Cassol, Eltz, Martins, Lemos, Lima \& Bueno, 2008). Este índice tem fundamentado diversos trabalhos sobre erosividade podendo-se destacar as pesquisas desenvolvidas por Peñalva-Bazzano, Eltz e Cassol (2010), Santos \& Eltz (2012).

Medeiros e Santos (2015) calcularam o balanço hídrico e o índice erosivo das chuvas aplicando os cenário otimista e persimista de mudanças climáticas para o município de Cabaceiras-PB. Os dados mensais e anuais pluviais e térmicos média do ar referente ao período de 1926-2010. Os resultados demonstraram que os cenários otimista (B2) e pessimista (A2), indicaram situações críticas das espécies do solo, ocasionando perdas para os lençóis d'água e inviabilizando certos cultivos de sequeiro. Mostraram que a área estudada enquadrava-se como sendo de alta erosividade.

Gonçalves, Sampaio, Jesus \& Leão (2015) mostraram que os riscos erosivos estão relacionado à porosidade, que interfere na quantidade do deflúvio das camadas rochosas, e 
contribuindo para uma maior deformação tectônica e à presença de zonas de cisalhamento ou das intensidades das fraturas.

Medeiros, Gomes Filho \& Costa Neto (2014) estimaram o índice erosivo pluvial para São João do Cariri, PB visando o desenvolvimento de melhores manejos e aproveitamento do solo da área estudada. Os dados de pluviais corresponderam ao período de 1911 a 2011. Através da equação determinada por Wischmeier, Jonhson, Cross \& Smith $(1958 ; 1978)$ os maiores índices de erosividade registraram-se nos meses de janeiro a julho que coincidem com o início do período chuvoso e com o da capacidade de campo em valores máximos e para os meses de agosto a dezembro ocorreram os menores índices erosivo correspondente ao período seco.

Aquino, Silva, Freitas Curi, Mello \& Avznzi (2012), ponderaram a quantidade, intensidade e duração das precipitações, em relação ao clima, aceitaram valores erosivos adqequado para a área estudada.

Conforme Jakob (2012), a krigagem é considerada uma boa metodologia de interpolação de dados. Ela utiliza o dado tabular e sua posição geográfica para calcular as interpolações. Utilizando o princípio da Primeira Lei de Geografia de Tobler, que diz que unidades de análise mais próximas entre si são mais parecidas do que unidades mais afastadas, a krigagem utiliza funções matemáticas para acrescentar pesos maiores nas posições mais próximas aos pontos amostrais e pesos menores nas posições mais distantes, e criar assim os novos pontos interpolados com base nessas combinações lineares de dados.

O método de krigagem se diferencia de outros métodos de interpolação pela forma de atribuição dos pesos. Segundo Yamamoto \& Landin (2015), para compreender a variação espacial do processo aleatório subjacente, deve-se levar em consideração a possibilidade de que o valor em cada ponto no espaço está conexo com valores obtidos em pontos situados a certa distância, sendo razoável supor que a influência é tanto maior quanto menor for a distância entre os pontos.

Berveglieri, Meneguette Junior \& Piteri (2011) mostraram que a geoestatística, de modo geral, desenvolve e aplica modelos em representações de fenômenos naturais cujas propriedades variam conforme a posição espacial dos pontos observados. A krigagem compreende um conjunto de técnicas geoestatísticas de ajuste usadas para aproximar dados pelo princípio que: fixado um ponto no espaço, os pontos no seu entorno são mais relevantes do que os mais afastados. Isto pressupõe a existência de dependência entre os dados, exigindo saber até onde espacialmente esta correlação importa de acordo com Isaaks \& Smivastav (1989). A técnica consiste em estimar valores médios e também uma medida de acuracidade 
(CC BY 4.0) | ISSN 2525-3409 | DOI: http://dx.doi.org/10.33448/rsd-v9i7.4218

dessa estimativa. Seus pesos são calculados com base na distância entre a amostra e o ponto estimado; na continuidade espacial e no arranjo geométrico do conjunto conforme afirma Bettini (2007).

$\mathrm{Na}$ bacia hidrográfica do alto curso do rio Paraíba agrupam várias ações de tipos de uso e ocupação do solo, tais como, agropecuária, pastagens, ocupações urbanas, trilhas ecológicas, turístico e lazer. Sobre este aspecto objetiva-se estudar a variabilidade geoespacionalizada gerando cartas do índice erosivo pluvial $\left(\mathrm{EI}_{30}\right)$ mensal e anual com base na equação universal de perda do solo, tempo de retorno, probabilidade e classificação erosiva além do coeficiente de chuva na área estudada.

\section{Metodologia}

A Bacia Hidrográfica do rio Paraíba (BHRPB), com área de 20.071,83 km², compreendida entre as latitudes $6^{\circ} 51^{\prime} 31^{\prime \prime}$ e $8^{\circ} 26^{\prime} 21^{\prime \prime}$ Sul e as longitudes $34^{\circ} 48^{\prime} 35^{\prime \prime}$; e $37^{\circ} 2^{\prime} 15^{\prime \prime}$; Oeste de Greenwich, é a segunda maior do Estado, pois abrange 38\% do seu território, abrigando 1.828.178 habitantes que correspondem a $52 \%$ da sua população do estado. Considerada uma das bacias mais importante do semiárido nordestino, ela é composta pela sub-bacia do Rio Taperoá e Regiões do Alto, Médio e Baixo Curso do rio Paraíba. (Figura 1).

Figura 1. Representação da bacia hidrográfica do rio Paraíba. Na porção sudoeste, seu Alto curso.

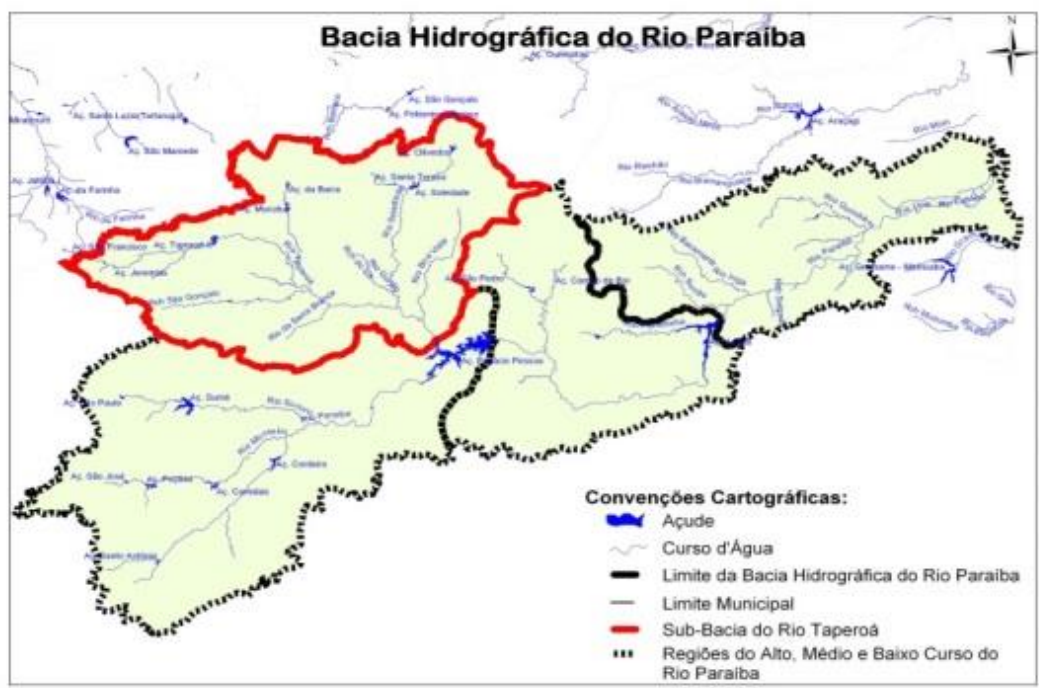

Fonte: AESA (2016). 
Na Figura 1 têm-se o contorno da bacia hidrográfica do alto curso do rio Parnaíba e nossa área de trabalho esta em destaque para a cor vermelha.

A bacia engloba, total ou parcialmente 18 municípios (Tabela 1 mostra os nomes dos municípios, as coordenadas geográficas (latitude, longitude e altitude), seguidamente do período de estudo) paraibanos distribuídos entre as microrregiões do Cariri Ocidental e Oriental do Estado.

Tabela 1. Relação dos municípios, coordenadas geográficas latitudes, longitudes (grau e minuto), altitude (m) e período de observações.

\begin{tabular}{lcccc}
\hline Municípios/Coordenadas & Latitude & Longitude & Altitude & Período \\
\hline Barra de São Miguel & $-7,45$ & $-36,19$ & 520 & $1962-2018$ \\
Cabaceiras & $-7,29$ & $-36,17$ & 338 & $1926-2018$ \\
Camalaú & $-7,53$ & $-36,49$ & 565 & $1962-2018$ \\
Caraúbas & $-7,43$ & $-36,29$ & 460 & $1931-2018$ \\
Congo & $-7,47$ & $-36,39$ & 500 & $1962-2018$ \\
Coxixola & $-7,37$ & $-36,36$ & 465 & $1962-2018$ \\
Monteiro & $-7,53$ & $-37,07$ & 590 & $1911-2018$ \\
Prata & $-7,41$ & $-37,04$ & 600 & $1962-2018$ \\
São João do Tigre & $-8,04$ & $-36,50$ & 616 & $1934-2018$ \\
São José dos Cordeiros & $-7,23$ & $-36,48$ & 600 & $1963-2018$ \\
S. Sebastião Umbuzeiro & $-8,09$ & $-37,00$ & 600 & $1962-2018$ \\
Serra Branca & $-7,28$ & $-36,39$ & 450 & $1962-2018$ \\
\hline
\end{tabular}

Fonte: Medeiros (2020).

A bacia é composta por regiões afligidas por eventos sinóticos locais, regionais e de larga escala provocadores de chuvas como a Zona de Convergência Intertropical (ZCIT) e as contribuições dos sistemas de Vórtices Ciclônicos de Altos Níveis (VCANs) quando em atividade sobre o NEB, além dos efeitos decorrentes dos ventos alísios de nordeste em conjunto com os efeitos de brisa marítima, auxiliados pela formação dos vórtices Ciclônicos do Atlântico Sul (VCAS) e das formações das linhas de instabilidade (LI), o Padrão do Dipolo (PD) no Oceano Atlântico Tropical e as perturbações ondulatórias no campo dos ventos alísios, proporcionando eventos de secas, enchentes, inundações, alagamentos, transbordamento de rios, açudes, barreiros, lagoas, lagos, córregos e córregos; na sua maioria, o escoamento dos rios nas cabeceiras é temporário devido à má distribuição pluviométrica. $\mathrm{Na}$ região, o período chuvoso com os aumentos das suas cotas pluviométricas provoca aumento significante no escoamento em que a maioria é represada em grandes e médias barragens e 
seu excesso após os represamentos escoa lentamente para o Oceano em virtude do relevo e de seus cursos básico das águas em conformidade com Medeiros (2016).

$\mathrm{Na}$ BHRPB predomina a existência de dois tipos climáticos conforme classificação climática de Köppen \& Geison (1928, 1931), os tipos climaticos são do tipo "BSh" e "As" estando em conformidade Alvares, Stepe, Sentelha, Gonçalves e Spanovck, (2014).

Os dados mensais e anuais pluviais foram cedidos pela Superintendência de Desenvolvimento do Nordeste (SUDENE, 1990) e fornecidos pela Agência Executiva de Gestão das Águas do Estado da Paraíba (AESA, 2019). A utilização dos dados foi procedida de análise no tocante à sua consistência, homogeneização e no preenchimento de falhas em cada série. Realizaram-se os preenchimentos de falhas pelo método da média ponderada pelo o inverso da distância ao quadrado realizados em planilhas eletrônicas por Medeiros (2016).

Para estimar o índice pluvial erosivo aplicou-se a metodologia proposta por Wischmeier de Smith (1971) e Wischmeier, Johnson \& Cross $(1958,1978)$ e a equação de Bertoni et al. (1999), dada por

$$
\mathrm{EI}_{30}=67,355\left(\mathrm{r}^{2} / \mathrm{P}\right) \mathrm{e}^{0,85}
$$

Em que:

$\mathrm{EI}_{30}$ - é a média mensal do índice erosivo, em MJ.mm.ha ${ }^{-1} \cdot \mathrm{h}^{-1} \cdot \mathrm{ano}^{-1}$;

$\mathrm{r}^{2}$ - é o índice pluvial médi mensal, em mm;

$\mathrm{P}$ - é a precipitação média anual, em mm.

Segundo Barbosa Iosrt, Schiessl, Maciel. (2000) e Menezes e Leite (2011) o fator R permite avaliar o potencial erosivo das chuvas de determinado local, dado por:

$$
R=\sum_{1}^{12} E I_{30}
$$

Após os cálculos dos índices anuais de erosividade da chuva dos municípios que entorna a BHRPB, foi calculado o período de retorno dado por:

$$
\mathrm{T}+(\mathrm{N}+1) / \mathrm{m}
$$

Onde:

T é o período de retorno, no qual o índice de erosividade é igualado ou excedido;

$N$ o número de anos da série de dados, e

$m$ o número de ordem do índice de erosividade, quando a série de dados de erosividade é colocada em ordem decrescente de magnitude.

O cálculo de probabilidade de ocorrência foi realizado por:

$$
\operatorname{Pr}=100 / \mathrm{T}
$$


Onde:

Pr é a probabilidade de ocorrência e

T o período de retorno.

Aplicou-se a lei de probabilidade logarítmica e a teoria de valores extremos (Schwab Fagmeier, Elliot e Frevent 1981).

O índice de erosividade da chuva foi classificado de acordo com a Tabela 2.

Tabela 2. Classificação do Índice de Erosividade anual.

\begin{tabular}{cc}
\hline Erosividade $\left(\mathrm{MJ} \mathrm{mm} \mathrm{ano}^{-1} \mathrm{ha}^{-1} \mathrm{~h}^{-1}\right)$ & Classe de Erosividade \\
\hline $\mathrm{R} \leq 2452$ & Baixa erosividade \\
$2452<\mathrm{R} \leq 4905$ & Média erosividade \\
$4905<\mathrm{R} \leq 7357$ & Baixa/alta erosividade \\
$7357<\mathrm{R} \leq 9810$ & Alta erosividade \\
$\mathrm{R}>9810$ & Muito Alta erosividade \\
\hline
\end{tabular}

Fonte: Schwab Fagmeier, Elliot e Frevent (1981).

Para a análise da distribuição mensal e anual da percentagem acumulada da erosividade, foram obtidos os valores relativos deste índice a partir da divisão da erosividade média mensal pelo seu valor médio anual, gerando valores relativos mensais. Quando transformados para percentagens, esses valores relativos representam a porcentagem acumulada da erosividade para cada município em estudo, permitindo a avaliação da sua distribuição anual.

O cálculo do coeficiente de chuva, como proposto por Lombardi Neto (1977), cuja expressão é dada por:

$$
\mathrm{Rc}=\mathrm{Pm}^{2} / \mathrm{Pa}
$$

Onde:

Rc o coeficiente de chuva em mm;

Pm a precipitação média mensal em mm, e

Pa a precipitação média anual.

Os coeficientes de chuva $(\mathrm{Rc})$ para cada município foram correlacionados com os valores dos índices de erosividade através de regressão, objetivando avaliar relação entre a ocorrência da precipitação e as de perdas de solo. 
Em conformidade com Bertoni et al. $(1990 ; 2008 ; 2012)$ e como diversos estudos que abordam a erosividade da chuva, como: Carvalho, Cruz,, Pinto, Silva \& Guerral (2010), Aquino, Freitas, Curi, Mello e Avanzi (2012), Waltrick (2010), Bazzano, Eltz \& Cassol (2007), Cassol, Eltz, Martins, Leno, Lima \& Bueno(2008), Dias e Silva (2003), Colodro, Carvalho, Roque e Prado(2002) e Hickmann, Eltz, Cassol e Cogo(2008), a condição seria trabalhar com uma série de dados pluvial de pelos menos 30 anos de dados observados e registrados, embora seja possível estimar a erosividade com séries de dados mais curtas, conforme afirmam os autores Bertoni \& Lombarti Neto (1990) e Mannaerts \& Grabielis (2000). No desenvolvimento deste trabalho utilizou-se de uma série de dados de 105 anos, compreendido ente o período de 1913 a 2015.

Realizaram-se os preenchimentos de falhas pelo método da média ponderada pelo inverso da distância ao quadrado desenvolvido em planilhas eletrônicas por Medeiros (2016), após a etapa do preenchimento realizou-se as consistência e harmonizações da série pluvial da área de estudo.

\section{Resultados e Discussão}

As Figuras (2 a 14) têm-se as especializações da erosão mensal e anual máxima pelo método da krigagem na bacia hidrográfica do rio Paraíba, Brasil.

Os índices erosivos do mês de janeiro esta representado na Figura 2.

Figura 2. Índices erosivos do mês de janeiro.

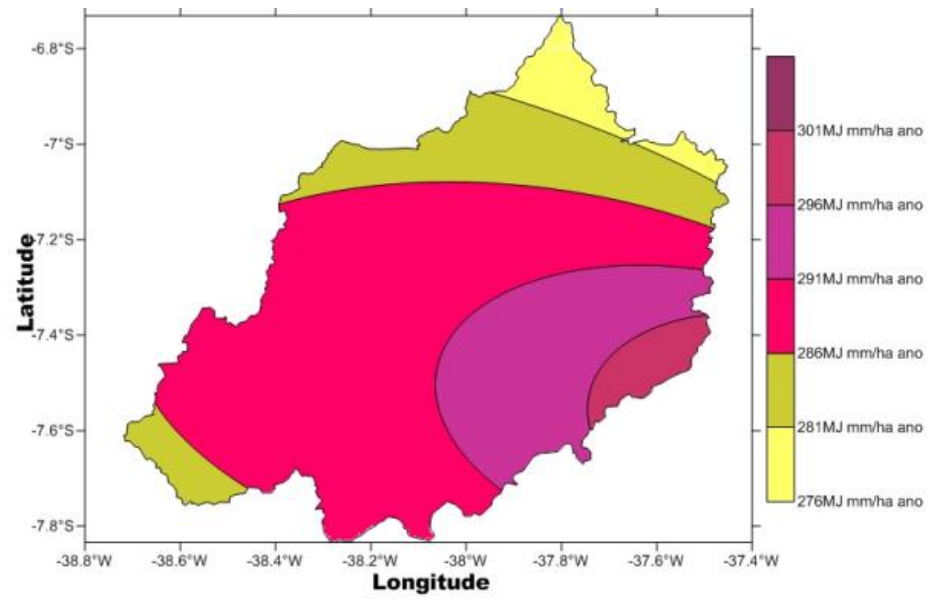

Fonte: Medeiros (2020). 
Destaca-se a redução crescente erosivo no sentido Sudeste/Norte Noroeste com variabilidade entre $291 \mathrm{Mj} . \mathrm{mm} . /$ há/h.ano a $281 \mathrm{Mj} . \mathrm{mm} . /$ há/h.ano, registra-se tembém no estremo sudoeste da área. Os menores poderes erosivivos loca-se no extremo norte.

A Figura 3 tem-se os índices erosivos máximo do mês de fevereiro, os indiceserosivos crescem no sentido norte/sul e de este para oeste.

Figura 3. Índices erosivos do mês de fevereiro.

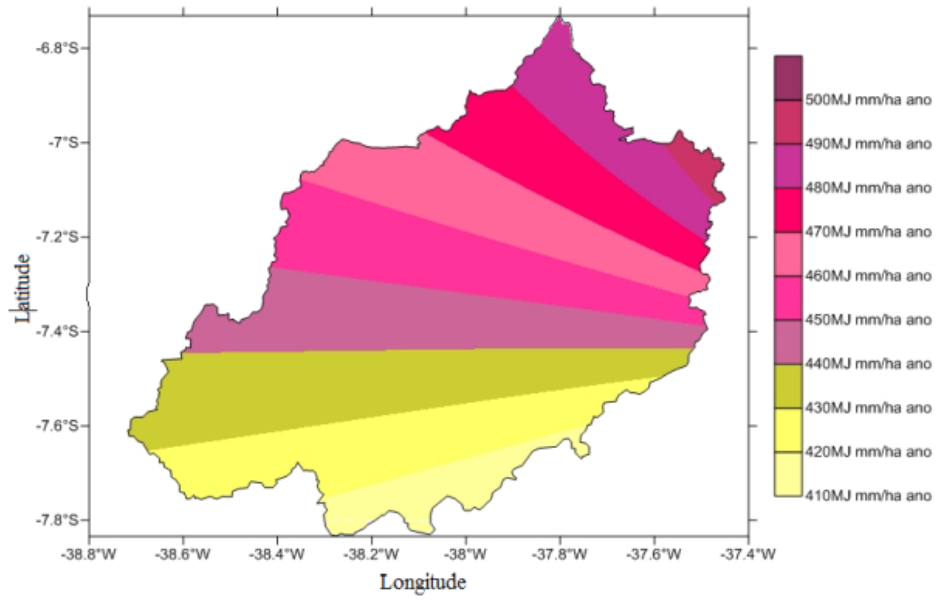

Fonte: Medeiros (2020).

Os baixos índices erosivos localiza-se no setor sul/sudeste, os valores altos da erosividade localiza-se no setor norte e noroeste, no setor leste a variabilidade erosiva fluiem entre 430 a 500 MJ. mm/há.h.ano.

Figura 4 observa-se as flutuações dos índices erosivos no mês de março com oscliações entre 840 Mj.mm/há.h.ano a 920 MJ.mm/há.h.ano. Destaca-se o acréscimo erosivo no sentido sudeste/sudoeste. Na posição sudeste registra 840 MJ.mm/há.h.ano os menores índices erosivos registrados no mês, os maiores índices erosivos ocorre na parte norte nordeste com 920 MJ.mm/há.h.ano.

Estudos próximos à área vem a corroboram com os resultados encontrados neste artigo, com o de Matos, Silva, Medeiros, Saboya, Borges e Galvão (2017), Medeiros e Santos (2015), Rosa, Souza, Costa e Souza (2016) que encontraram índices erosivos próximos. A proximidade entre os valores era esperada em função da similaridade da distribuição anual e comportamento da precipitação na região norte e leste do Brasil, se justificando pela intensidade da precipitação no período estudado de acordo com Marengo et al. (2008). 
Figura 4. Índices erosivos do mês de março.

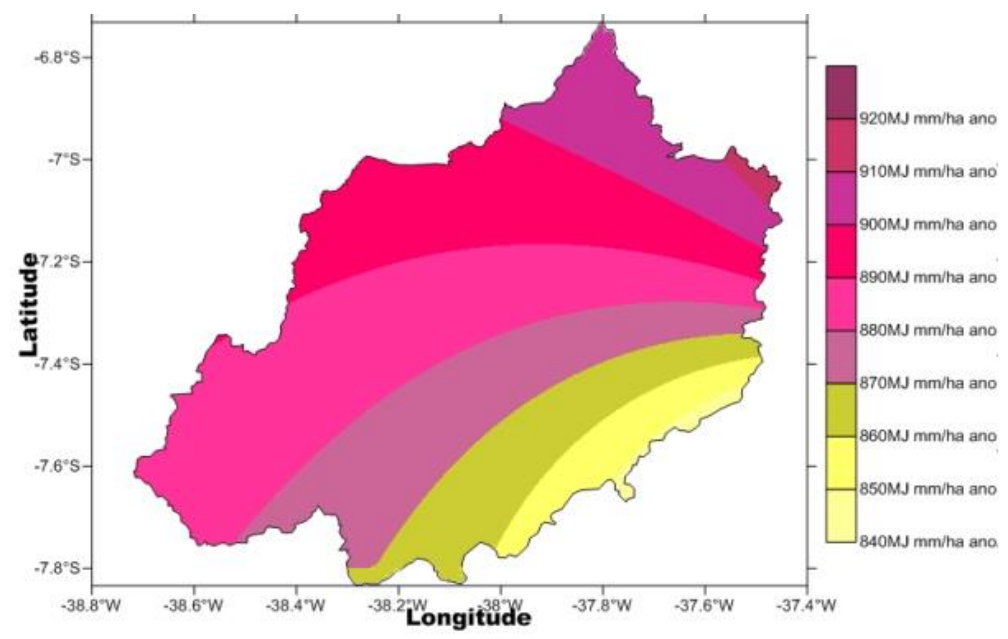

Fonte: Medeiros (2020).

O mês de abril (Figura 5) apresentou flutuações erosivas entre 640 MJ.mm/há.h.ano no setor sul e sudeste a $750 \mathrm{MJ} . \mathrm{mm} / \mathrm{há}$.h.ano no setor norte/nordeste, destaca o aumento erosivo em alagamento de área compreendido entre o setor leste/oeste.

Figura 5. Índices erosivos do mês de abril.

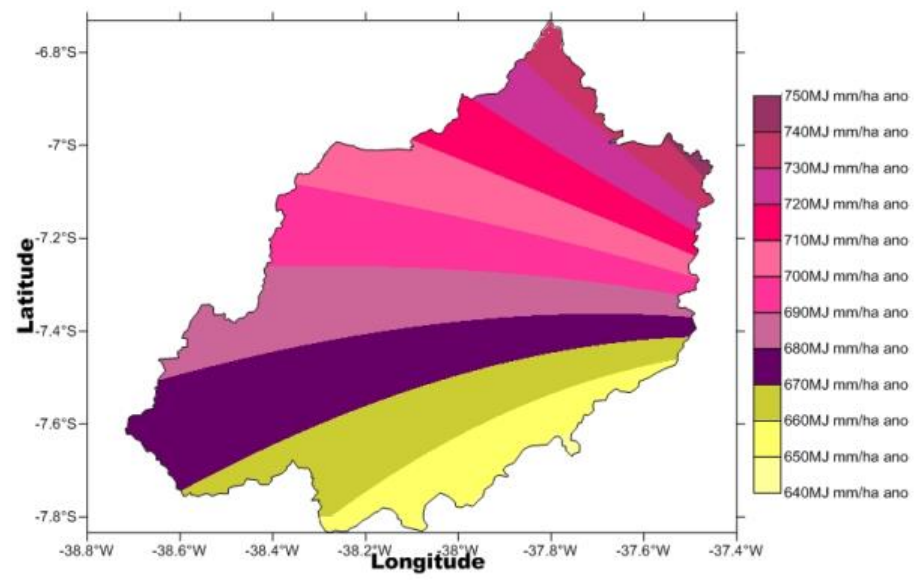

Fonte: Medeiros (2020).

$\mathrm{Na}$ região nordestes do Brasil, particularmente o estado de Pernambuco, estão vulneráveis aos processos de desertificação e, variabilidades de clima com eventos extremam e como secas severas, chuvas intensas conforme afirmação de Lacerda, Nobre, Sobral, Lopes e Assad (2016).O estudo vem a corroborar com os resultados deste trabalho.

O mês de maio (Figura 6) registra-se índices erosivos fluindo entre 296 a 312 MJ.mm/há.h.ano, observa-se aumento gradativo da erosão no sentido sudoeste nordeste, estes valores erosivos estão interligados ao regime de chuva da área estudada. 
Figura 6. Índices erosivos do mês de maio.

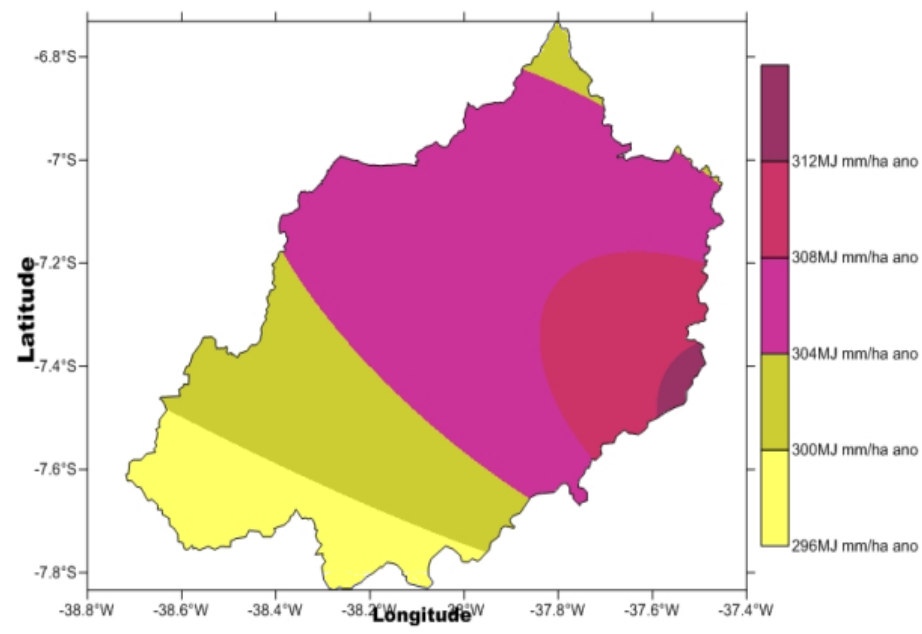

Fonte: Medeiros (2020).

Na Figura 7 observam-se as flutuações erosivas do mês de junho, registra-se aumento gradativo no sentido sudeste/nordeste com oscilações fluindo entre 106 a 121 MJ.mm/há.h.ano. A área degrada por erosividade são alagadas a oeste e com estreitamento em este demonstrando a fragilidade do solo na área de estudo.

Figura 7. Índices erosivos do mês de junho

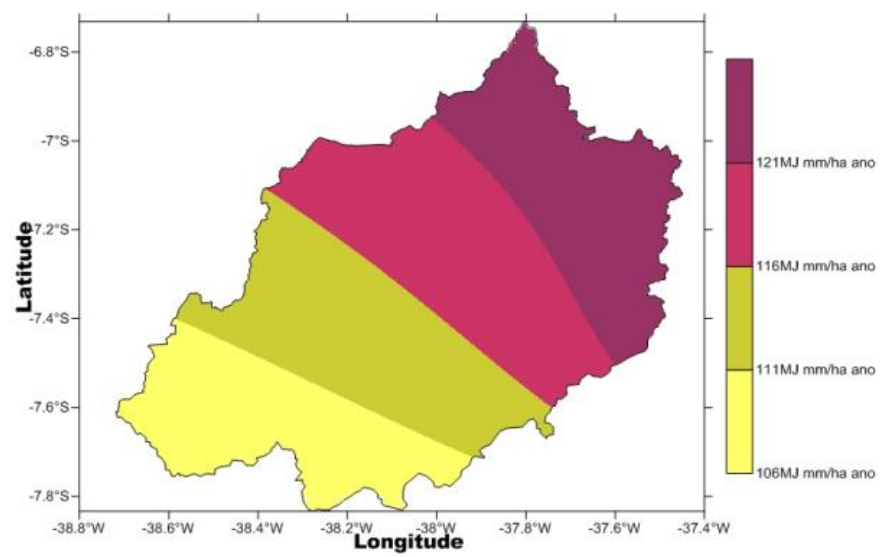

Fonte: Medeiros (2020).

Estudo desenvolvido por Medeiros, Gomes Filho \& Costa Neto. (2014) na área da bacia hidrográfica do rio Uruçuí Preto- PI corrobora com o estudo presente, mostrando as flutuações erosivas mensais na área de estudo.

Com a redução das chuvas e a predominância do período seco os índices erosivos fluviais são reduzidos e suas flutuações ocorrem entre 66 a 86 MJ.mm/há.h.ano (Figura 8), a erosão eólica tem pouca ou nenhum atividade na área estudada. 
Figura 8. Índices erosivos do mês de julho.

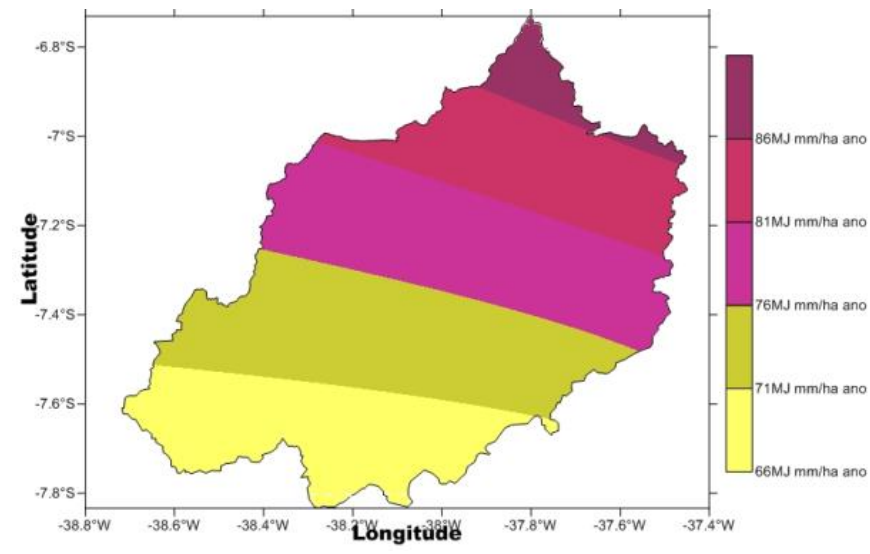

Fonte: Medeiros (2020).

Com oscilações entre 18 a 26 MJ.mm/há.h.ano, foram às condições erosivas do mês de agosto na BHRPB (Figura 9).

Figura 9. Índices erosivos do mês de agosto.

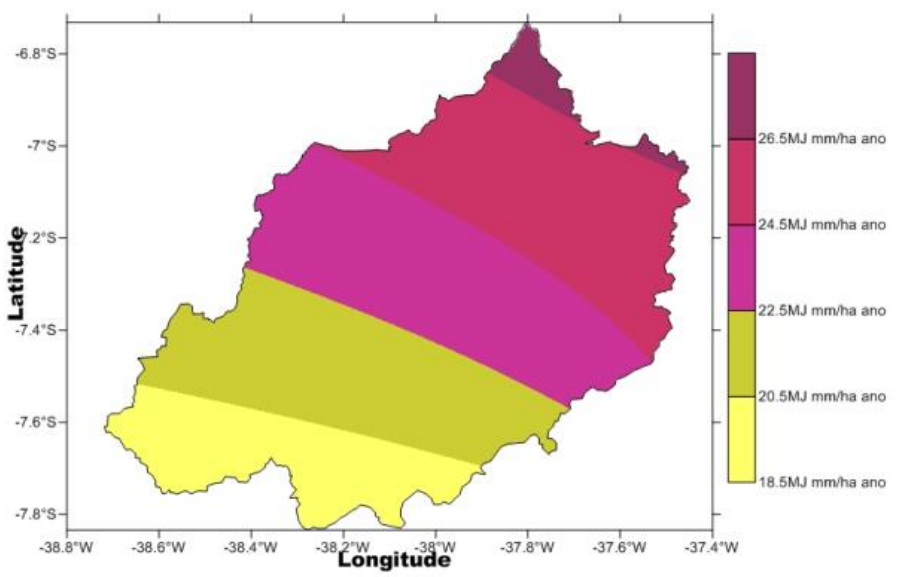

Fonte: Medeiros (2020).

As atividades antrópicas unificadas a distribuição e a variabilidade pluvial podem ocasionar consequências negativas como transtorno de rios, lagos, lagoas, enchentes, inundações de áreas urbanas/rural. As intervenções humanas ao meio físico vêm aumentando de forma substancial e o grau de risco dos locais em relação a alguns eventos climáticos podem se tornar em desastres (Nunes, 2016). Este estudo vem corroborar com os as variabilidades encontradas neste estudo.

Os índices erosivos do mês de setembro (Figura 10) na BHRPB registram oscilações entre 6 a 13 MJ.mm/há.h.ano, assim como as chuvas no referido mês são reduzidas. 
Figura 10. Índices erosivos do mês de setembro.

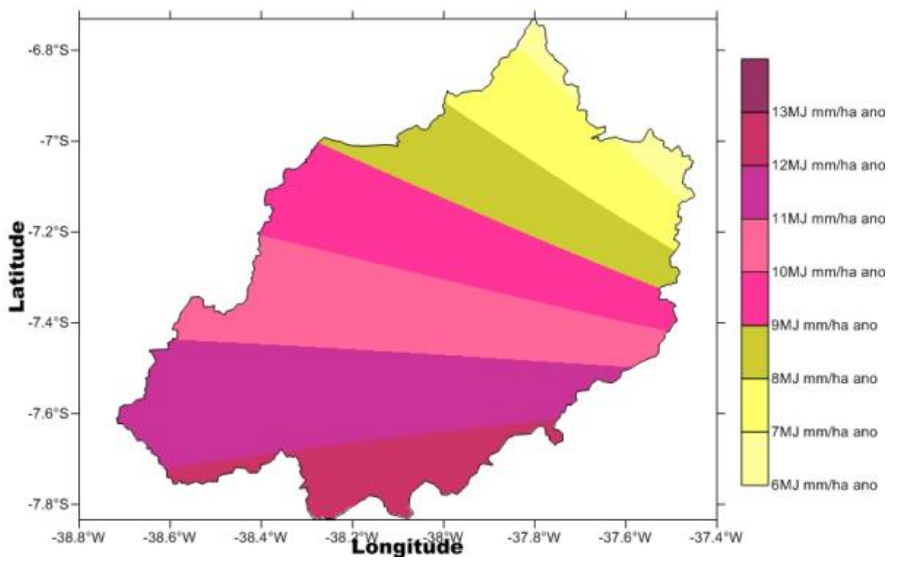

Fonte: Medeiros (2020).

Os índices erosivos do mês de outubro na área da BHRPB estão representados na Figura 11. Observam-se as flutuações erosivas crescentes no sentido sudeste/sudoeste, a expansão de área erosiva ocorre no sentido leste oeste com maior significância de alagamento da área erosiva no setor oeste.

Figura 11. Índices erosivos do mês de outubro.

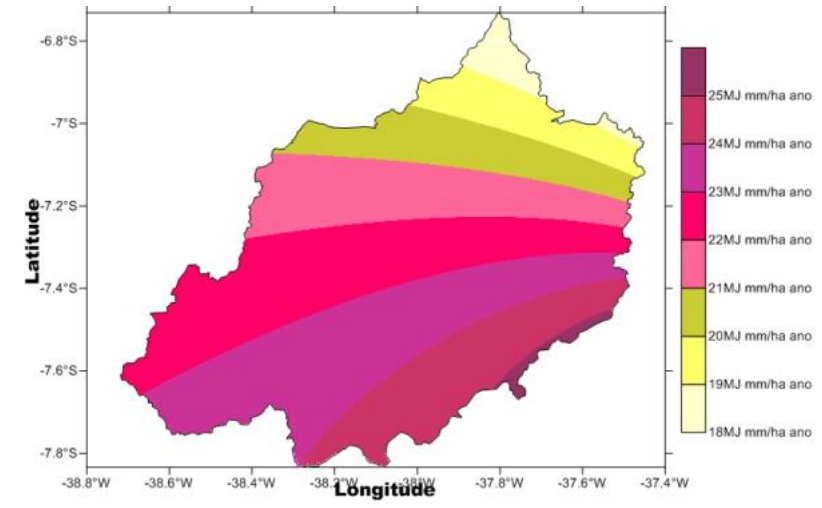

Fonte: Medeiros (2020).

No mês de novembro (Figura 12) a variabilidade erosiva flui entre 14 a 38 MJ mm/há.h.ano. Registram-se reduções erosivas no sentido sul/norte, assim como observamos os seus respectivos máximos e mínimos erosivos. Se justificando pela não ocorrência da precipitação no período estudado de acordo com Marengo \& Nobre. (2008). 
Figura 12. Índices erosivos do mês de novembro.

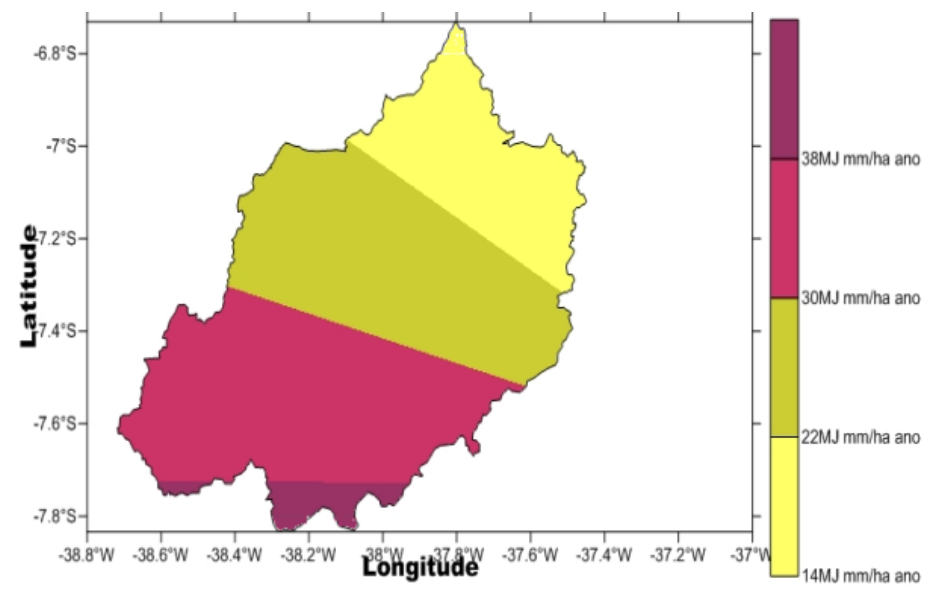

Fonte: Medeiros (2020).

Destacam-se os núcleos de máxima e mínima erosão nos setores sul e norte respectivamente. No setor central os índices erosivos fluem 88 a 98 MJ mm/há.h.ano. A variabilidade erosiva do mês de dezembro cresce no sentido norte/sul onde registram os seus mínimos e máximos erosivos. (Figura 13). Estudos similares como o de Medeiros, Kosmkinsky, Holanda \& Silva (2017) corroboram com os resultados obtidos neste artigo.

Figura 13. Índices erosivos do mês de dezembro.

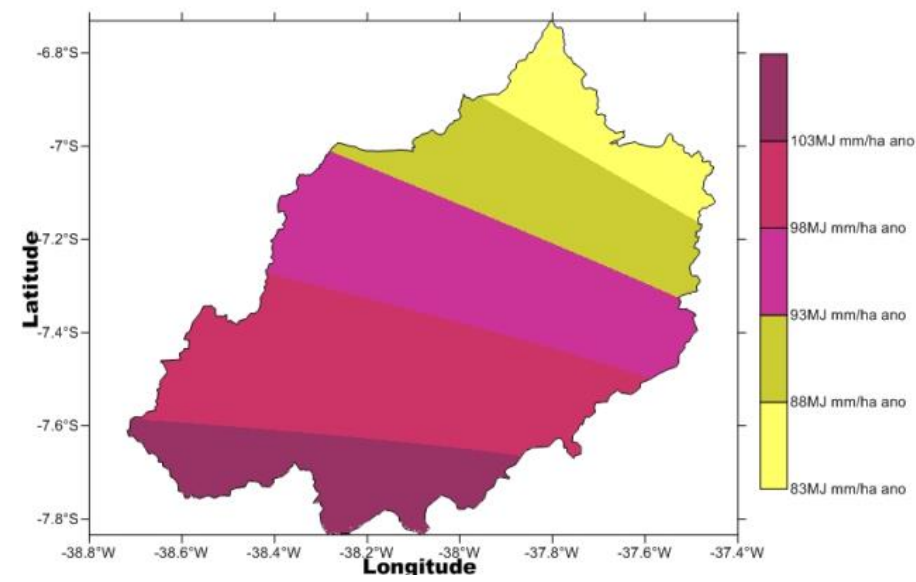

Fonte: Medeiros (20120).

Os índices pluviais são importantes para o setor socioeconômico, pois deles ocorrem a sobrevivência da agricultura familiar e de cerqueiro, os períodos de estiagem reduzem as reservas de águas nos mananciais e nas represas, dificultando os agricultores e a população 
(CC BY 4.0) | ISSN 2525-3409 | DOI: http://dx.doi.org/10.33448/rsd-v9i7.4218

urbana por água para sobrevivência, além de minimizar os índices erosivos em conformidade com Calasans, Levy \& Moreali (2008).

Na Figura 14 tem-se a geoespacialização dos índices erosivos anual da BHRPB, ocorrem aumentos erosivos no sentido sul/norte, o menor índice erosivo anual registra-se no setor sul/sudeste, na região central da BHRPB têm-se índices erosivos fluindo entre 2894 MJ.mm/há.h. ano a 2930 MJ.mm/há.h.ano, no setor norte/nordeste e sudoeste tem os altos índices erosivos fluindo entre 2984 MJ.mm/há.h.ano a 3020 MJ.mm/há.h.ano. Estes valores erosivos anuais estão condicionados as irregularidades pluviais e aos sistemas provocadores e/ou inibidores de chuvas da área estudada.

Figura 14. Índices erosivos anuais na BHRPB.

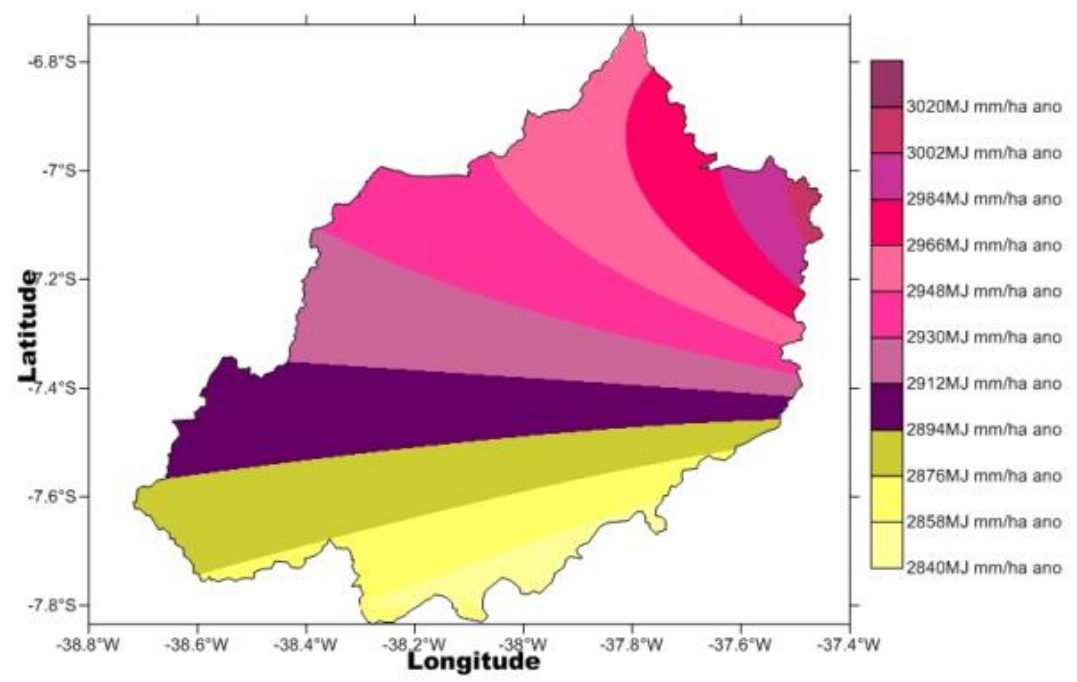

Fonte: Medeiros (2020).

Na Tabela 1 encontram-se os elementos estatísticos os quais foram utilizados por meio de software e por planilhas eletrônicas, calculando-se os referidos elementos abaixo relacionados.

Com média anual de 10.409,6 MJ.mm/há.h.ano e suas oscilações mensais fluindo entre 134,6 MJ.mm/há.h.ano no mês de setembro a 5006,4 MJ.mm/há.h.ano no mês de abril são os valores dos índices erosivos esperados no decorrer do tempo futuro para a área de estudo. As variabilidades das oscilações nos coeficientes de variância tem boa a ótima significância e seus valores podem serem acrescido positivamente ou negativamente aos dados da média. Os valores máximos e mínimos erosivos registrados foram causados pelas atividades dos fenômenos locais e regionais atuantes no período de estudo. 
A mediana é o valor mais provável de ocorrência. O desvio padrão poderá interferir com contribuições positiva e/ou negativa em relação aos valores da média e/ou mediana. $\mathrm{O}$ Coeficiente de variância com nível de significância baixa a moderado. Os valores máximos e mínimos absolutos erosivos estão interligados aos eventos pluviais e dos efeitos locais e regionais.

Foi demostrado por Katz (1991), Katz e Brown (1992) que a frequência relativa de eventos extremos depende das mudanças no desvio padrão e não apenas da média. Katz (1991) supõe que uma mudança em uma variável climática que possua distribuição de probabilidade poderá resultar em uma mudança na forma de sua distribuição.

Na Tabela 3 têm-se os parâmetros estatísticos (média, mediana, desvio padrão, coeficiente de variância e os valores máximos e mínimos) dos índices erosivos para a área da BHRPB.

Tabela 3. Parâmetros estatísticos dos índices erosivos para a área da BHRPB.

\begin{tabular}{ccccccc}
\hline Meses & Média & Mediana & $\begin{array}{c}\text { Desvio } \\
\text { padrão }\end{array}$ & $\begin{array}{c}\text { Coeficiente } \\
\text { variância }\end{array}$ & $\begin{array}{c}\text { Máximo } \\
\text { absoluto }\end{array}$ & $\begin{array}{c}\text { Mínimo } \\
\text { absoluto }\end{array}$ \\
\hline Jan & 3815,8 & 4172,8 & 1339,9 & 0,351 & 6617,0 & 1841,8 \\
Fev & 3342,0 & 4448,2 & 1139,3 & 0,341 & 5274,2 & 1636,2 \\
Mar & 4724,0 & 6037,0 & 1275,2 & 0,270 & 6434,1 & 2458,8 \\
Abr & 5006,4 & 6347,4 & 1196,3 & 0,239 & 6579,3 & 3073,3 \\
Mai & 2574,3 & 2140,2 & 1299,8 & 0,505 & 5371,6 & 1291,9 \\
Jun & 1122,2 & 973,4 & 420,2 & 0,374 & 1738,8 & 598,4 \\
Jul & 758,3 & 769,1 & 362,3 & 0,478 & 1514,0 & 356,2 \\
Ago & 329,1 & 198,2 & 260,8 & 0,792 & 841,3 & 53,1 \\
Set & 134,6 & 177,4 & 87,6 & 0,651 & 262,3 & 14,8 \\
Out & 564,7 & 1034,7 & 325,1 & 0,576 & 1076,3 & 98,6 \\
Nov & 552,6 & 155,4 & 513,6 & 0,929 & 1370,2 & 43,7 \\
Dez & 1197,4 & 1336,9 & 438,2 & 0,366 & 2047,8 & 573,2 \\
Anual & 10409,6 & 14039,9 & 2521,4 & 0,242 & 14039,9 & 6495,9 \\
\hline
\end{tabular}

Legenda: Valores em MJ mm/há.h. ano.

Fonte: Medeiros (2020). 
Na Tabela 4 Distribuição média anual da erosão; tempo de retorno; probabilidade; classificação; chuva anual e do coeficiente de chuva para a área da BHRPB no período de 1962-2018.

A classificação do índice de erosividade por município apresenta duas classes: de média erosividade e baixa erosividade. O período de retorno do fator erosividade da chuva na área da BHRPB oscila entre 4,1 anos no município de Prata a 9,1 anos em Cabaceiras com probabilidade de $11 \%$, demais valores erosivos, seu tempo de retorno e suas probabilidades estão exposto na Tabela 4. Os índices anuais e coeficiente de chuva são irregulares e seguem os fatores climáticos predominantes de chuva na região da BHRPB.

Tabela 4. Distribuição média anual da erosão; tempo de retorno; probabilidade; classificação; chuva anual e do coeficiente de chuva para a área da BHRPB no período de 1962-2018.

\begin{tabular}{lcccccc}
\hline \multirow{2}{*}{ Municípios } & \multicolumn{2}{c}{ Erosão Tempo de } & Probabilidade Classificação & Chuva & Coeficiente \\
& anual & retorno & erosão & Erosão & anual & chuva \\
\hline Barra São Miguel & 2163,9 & 6,1 & 6,1 & Baixa erosividad & 549,2 & 608,9 \\
Cabaceiras & 1423,4 & 9,1 & 9,1 & iaixa erosividade & 499,2 & 503,1 \\
Camalaú & 2815,1 & 4,6 & 4,6 & Tédia erosividade & 527,1 & 561,0 \\
Caraúbas & 2321,8 & 5,6 & 5,6 & iaixa erosividade & 541,3 & 591,5 \\
Congo & 2796,5 & 4,6 & 4,6 & Tédia erosividade & 380,7 & 292,6 \\
Coxixola & 2630,4 & 4,9 & 4,9 & Tédia erosividade & 664,3 & 891,1 \\
Monteiro & 2682,7 & 4,8 & 4,8 & Tédia erosividade & 478,8 & 462,9 \\
Prata & 3170,9 & 4,1 & 4,1 & Tédia erosividade & 407,6 & 335,5 \\
São J. Cordeiros & 3044,3 & 4,2 & 4,2 & Tédia erosividade & 336,4 & 228,4 \\
São João Tigre & 2555,8 & 5,1 & 5,1 & Tédia erosividade & 462,7 & 432,3 \\
SãoS. Umbuzeiro & 2655,5 & 4,9 & 4,9 & Tédia erosividade & 615,0 & 763,7 \\
Serra Branca & 2670,8 & 4,8 & 4,8 & Tédia erosividade & 481,0 & 467,1 \\
\hline
\end{tabular}

Legenda: Erosão (MJ mm ano ${ }^{-1} \mathrm{ha}^{-1} \mathrm{~h}^{-1}$ ); Tempo de retorno (Anos); Probabilidade (\%); Chuva (mm); Coeficiente chuva (mm). Fonte: Medeiros (2020)

Diversos estudos próximos à área vêm a corroboram com os resultados encontrados com índices próximos de erosividade em Cabaceiras - PB o índice erosivo foi de 11.701,1 MJ.mm ha ${ }^{-1}$ ano $^{-1}$ Medeiros, Matos, Silva \& Saboya (2015). A erosividade em Barbalha (CE) foi de 7.849,0 MJ. mm ha- ${ }^{-1} \mathrm{~h}^{-1}$ ano $^{-1}$ Matos, Silva, Medeiros, Saboya, Borge \& Galvão (2017), A proximidade entre os valores era esperada em função da similaridade da distribuição anual 
Research, Society and Development, v. 9, n. 7, e472974218, 2020

(CC BY 4.0) | ISSN 2525-3409 | DOI: http://dx.doi.org/10.33448/rsd-v9i7.4218

e comportamento da precipitação na região norte e leste do Brasil. Valores próximos também foram encontrados em Quedas do Iguaçu (PR) (12.169 MJ.mm ha-1 $\mathrm{h}^{-1} \mathrm{ano}^{-1}$ ), por Waltrick (2010), se justificando pela intensidade da precipitação no período estudado. Estudos como o de Fortaleza (CE) (2,2 anos) por Dias \& Silva (2003), Conceição do Araguaia (PA) (2,7 anos) por Oliveira Jr. (1996), entre tantos vem a corroborar com os resultados da pesquisa em desenvolvimento.

$\mathrm{Na}$ Figura 15 tem-se a curva do período de retorno da erosividade anual nos municípios de entorno da BHRPB no período de 1962 a 2018. O tempo de retorno da erosividade na área de estudo oscila entre 1 a 9 anos.

Figura 15. Curva do período de retorno da erosividade anual nos municípios de entorno da BHRPB. Fonte: Autor.

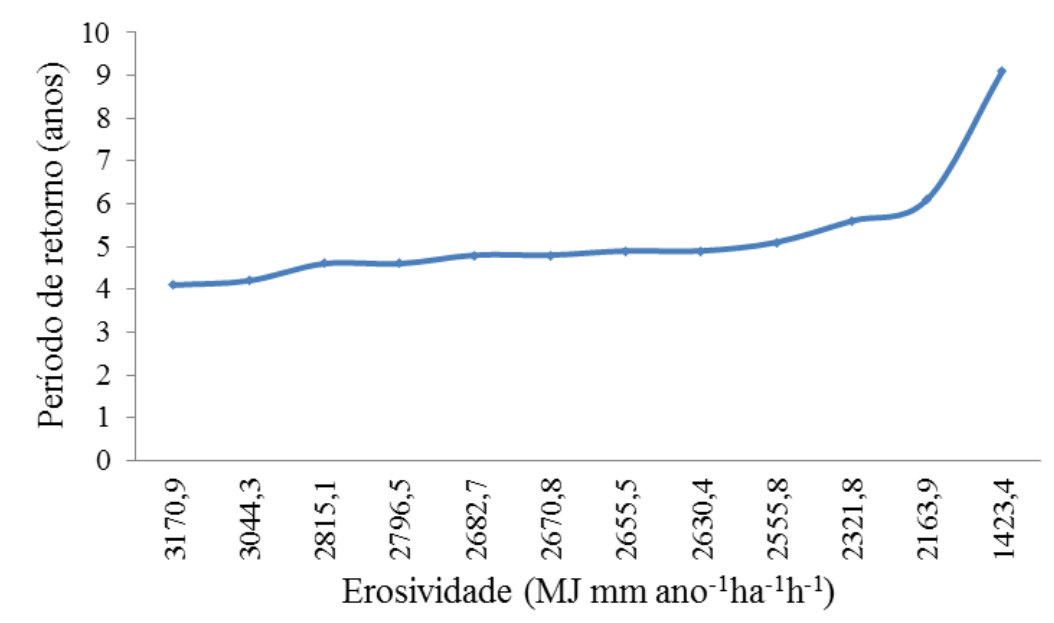

Fonte: Medeiros (2020)

A probabilidade de uma ocorrência de erosividade anual igual ou superior ao fator $\mathrm{R}$ calculado é de $50 \%$ pelo menos uma vez a cada um ano. No intervalo erosivo entre 3170,9 a 1423,4 MJ.mmha ${ }^{-1} \mathrm{~h}^{-1}$ ano $^{-1}$ tem-se probabilidade de ocorrências de 6 a $11 \%$ conforme Figura 16. 
Figura 16. Curva de probabilidade de ocorrência da erosividade anual nos municípios de entorno da BHRPB.

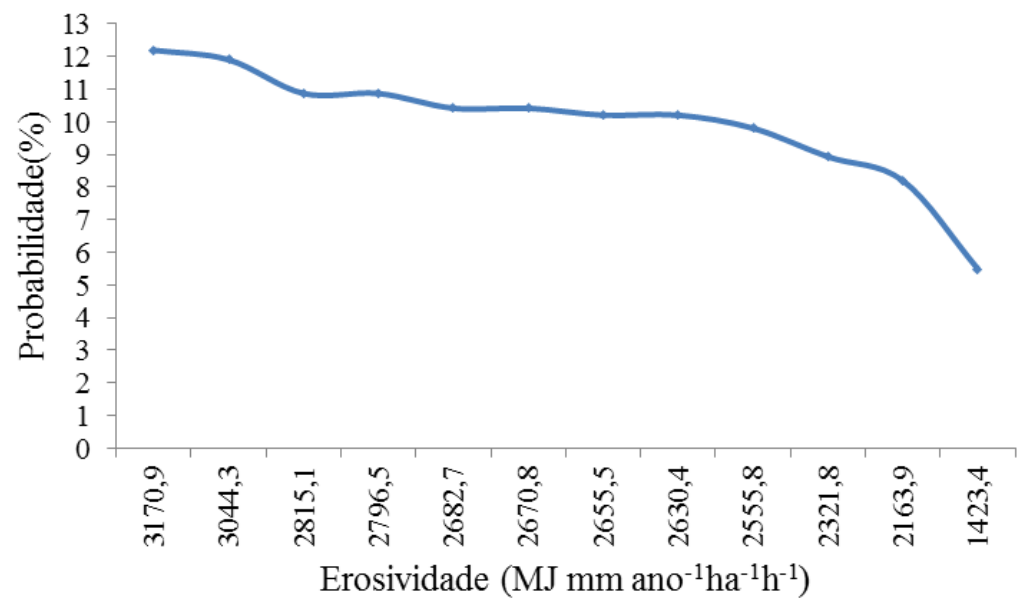

Fonte: Medeiros (2020)

A leitura dessa curva (Figura 16) permite estimar os períodos de retorno e probabilidades de ocorrência para diferentes valores de erosividade.

\section{Considerações Finais}

As formas erosivas atualmente, tanto pela água como pelo vento, são responsável por cerca de $56 \%$ e $28 \%$, respectivamente, da degradação dos solos no mundo. Os problemas de erosão, na BHRPB, são resultantes da combinação de um rápido processo de ocupação e tecnificação do território, solo frágeis e de um regime climático propício a sua ocorrência de forma intensa. Sendo que estes processos não são somente de formas físicas.

O modelo da interpolação da Krigagem teve significâncias com os resultados apresentados.

A vulnerabilidade erosiva se dá em função das características das unidades do relevo, a combinação das formas do uso e ocupação do solo, desordenado sem técnicas de manejo e as práticas não conservacionistas, o desmate, as queimadas, e a exploração do carvão e a ação do homem são os principais fatores causadores da erosibilidade em toda bacia.

Sabe-se que os problemas ambientais transcorridos em determinada área interferem em toda a bacia causando impactos diretos de assoreamento e de degradação.

Para a BHRP existe a necessidade do planejamento prévio de terrenos para implantação de pomares e de projetos agrícolas frutíferos, para que não ocorra o 
deslocamento de terra, amparado num monitoramento das mudanças que ocorrem no solo, principalmente em regiões de encosta, considerando-se as curvas de níveis do terreno.

As áreas agricultáveis da BHRPB e seu entorno localizam-se ao longo de todo seu território tendo, suas regiões climáticas com diferentes potenciais erosivos. Logo, o conhecimento deste potencial será de enorme valor para escolha de práticas de manejo do solo visando controlar o seu processo erosivo.

A concretização deste estudo vem a contribuir para políticas de planejamento e gestão regional e/ou local, assim como, contribuirá como subsidio a novos desenvolvimentos de estudos que enfoquem as questões aqui apresentadas.

A bacia hidrográfica do alto curso do rio Parnaíba dever ser monitorada quanto aos seus índices pluviais e erosiva, pois para muito habitantes ribeirinhos o leitos do rio apresenta-se com altos índices de erosividades e o curso d’água esta cada vez mais estreito, dificultando a navegação e a pesca.

\section{Referências}

AESA. (2016). Agência Executiva de Gestão das Águas do Estado da Paraíba. www.aesa.gov.br.

Alvares, CA, Stape, JL, Sentelhas, PC, Gonçalves, JLM \& Sparovek, G. (2014). Köppen's climate classification map for Brazil. Meteorologische Zeitschrift, 22(1): 711-728.

Alves, TLB. \& Azevedo, PV. (2013). Analise da distribuição decadal e tendência da precipitação pluvial no município de Caraúbas-PB. In: Workshop Internacional sobre Agua no Semiárido Brasileiro, 1, 2013, Campina Grande-PB. Anais... Campina Grande: UFCG, 5p.

Andrade, AG.; Freitas, P.L. \& Landers, J. (2010)Aspectos Gerais Sobre o Manejo e Conservação do Solo e da Água e as Mudanças Ambientais, in: Prado, R.B., Turetta, A.P.D., Andrade, A.G. (Org.), Manejo e Conservação do Solo e da Água no Contexto das Mudanças Ambientais. EMBRAPA Solos, Ministério da Agricultura, Pecuária e Abastecimento, Rio de Janeiro, p. 25-40. 
Aquino, R.; Silva, MLN.; Freitas, DAF.; Curi, N.; Mello, CR. \& Avanzi, JC. (2012) Spatial variability of the rainfall erosivity in southern region of Minas Gerais state, Brazil. Ciência e Agrotecnologia 36:533-542.

Ataíde, RS. \& Furtado, TV. (2014). Importância da utilização das normais climatológicas para análise de variação climática. Instituto Federal de Educação, Ciência e Tecnologia de Santa Catarina. Curso técnico de meteorologia, p.27.

barbosa, GS.; Iost, C.; SchiessL, M.A. \& Maciel, G.F. (2000). Estimativa da erosividade da chuva (R) na Bacia Hidrográfica do rio Manoel Alves Grande localizado no cerrado tocantinense. In: Congresso brasileiro de meteorologia, 16. Belém.

Bazzano, MGP.; Eltz, FLF. \& Cassol, EA. (2007).Erosividade, coeficiente de chuva, padrões e período de retorno das chuvas de Quaraí, RS. R. Bras. Ci. Solo.32:1205-1217,

Bertoni, J. \& Lombardi Neto, F. (2012). Conservação do solo. 2. E.São Paulo: Ícone, 355p.

Bertoni, J. \& Lombardi Neto, F. (2008). Conservação do Solo, 6 ed. Ícone, São Paulo.. 382p.

Bertoni, J. \& LombardI Neto, F. (1999).Conservação do solo. São Paulo: Ícone;

Bertoni, J. \& Lombardi Neto, F. (1990). Conservação do solo. 2.ed. São Paulo: Ícone,. 385p.

Berveglieri, A.; Meneguette Junior, M. \& Piteri, MA. (2011). Aplicação do interpolador krigagem em modelos digitais de terrenos comparando-se os casos de isotropia e anisotropia. In: Simpósio Brasileiro de Sensoriamento Remoto, 15. SBSR, Curitiba: Anais...INPE, p.72227229.

Calasans, NAR.; Levy, MCT. \& Moreau, M. (2008). Interrelações entre clima e vazão. In: Schiavetti, A.; Camargo, A. F. M. Conceitos de bacia hidrográficas: teorias e aplicações. Ilhéus: Editus, p. 67-90. 
Carvalho, DF.; Cruz, ES.; Pinto, MF.; Silva, LDB. \& Guerra, JG.M. (2010). Características da chuva e perdas por erosão sob diferentes práticas de manejo do solo. Revista. Bras. Eng. Agríc. Ambiental. 13(1):3-9,

Cassol, EA.; Eltz, FLF.; Martins, D.; Lemos, A. M.; Lima, V. S. \& Bueno, A. C. (2011). Erosividade, padrões hidrológicos, período de retorno e probabilidade de ocorrência das chuvas em São Borja, RS. Revista Brasileira de Ciência do Solo, Viçosa, 32(3):1239-1251.

Colodro, G.; Carvalho, MP.; Roque, CG. \& Prado, RM. (2002). Erosividade da Chuva: Distribuição e correlação com a precipitação pluviométrica de Teodoro Sampaio (SP). Revista Bras. Ci. Solo. 26:809-818,

Dias, AS. \& Silva, JRC. (2003). A Erosividade das chuvas em Fortaleza (CE). I distribuição, probabilidade de ocorrência e período de retorno - primeira aproximação. Revista Brasileira Ci. Solo. 27:335-345,

Gonçalves, JH.; Sampaio, AR.; Jesus, JDA. \& Leão, R. (2008). GEOBANK. Disponível: Acesso: ago 2019.

Hickmann, C.; Eltz, F. L. F.; Cassol, E. A. \& Cogo, C. M. (2008). Erosividade das chuvas em Uruguaiana, RS, determinada pelo Índice EI30, com base no período de 1963 a 1991. R. Bras. Ci. Solo. 32:825-831,

Isaaks, EH.; (1989). Srivastava, RM. An introduction to applied geostatistics. New York: Oxford University Press, 561p..

Jakob, AAE. (2002).A krigagem como método de análise de dados demográficos. In: Encontro da Associação Brasileira de Estudos Populacionais, 13. Ouro Preto.

Katz, RW. (1991). Towords a statistical paradign for climate change. Preprints, 7TH Conference on Applied climatology, American Meteorological Society, Boston,

Katz, RW. \& Brown, BG. (1992). Extreme Events inaChanging Climate: Variability is more important than averages. Climate Change. 21(3):289-302. 
Köppen, W. \& Geiger, R. (1928). Klimate der Erde. Gotha: Verlagcondicionadas. Justus Perthes. n.p.

Lacerda, FF.; Nobre, P.; Sobral, MCM.; Lopes, GMB \& Assad, ED. (2016). Tendência do Clima do Semiárido Frente as Perspectivas das Mudanças Climáticas Globais; O Caso de Araripina, Pernambuco. Revista do Departamento de Geografia, 31:132-141.

Lombardi Neto, F. (1977_. Rainfall erosivity - Its distribution and relationship with soil loss at Campinas, Brasil. 1977. 53f. Dissertação (Mestrado em Agronomy) - Purdue University, West Lafayette,

Mannaerts, CM. \& Gabriels, D. (2000). Rainfall erosivity in Cape Verde. Soil Tillage Res. 55:207-212,

Marengo, JA. (2008). Mudanças climáticas, condições meteorológicas extremas e eventos climáticos no Brasil. In: Fundação Brasileira para o Desenvolvimento Sustentável (org.). Mudanças climáticas e eventos extremos no Brasil. Disponível em <http://www.fbds.org. br/fbds/IMG/pdf/doc-504.pdf>.

Matos, RM.; Silva, PF.; Medeiros, RM.; Saboya, LMF.; Borges, VE. \& Galvao ST. (2017). Erosividade da chuva no período de 1973 a 2013 no município de Barbalha - CE. Revista Brasileira de Geografia Física. 10:641 - 649,

Medeiros, RM; Kozmhinsky, M.; Holanda, RM. \& Silva, VP. (2017). Estimativa da erosão pluvial na bacia hidrográfica do rio Uruçuí Preto - Piauí, Brasil. Revista Brasileira de Agrotecnologia. 7(3):81 - 90,

Medeiros, RM. (2016). Estudo agrometeorológico para o estado da Paraíba. p.120.

Medeiros, R. M. (2016). Planilha eletrônica para preenchimento de falhas pluviais pelo método da média ponderada pelo inverso da distância ao quadrado. 
Medeiros, RM.; Matos, R. M.; Silva, P. F. \& Saboya, L. M. F. (2015). Cálculo do balanço hídrico e da erosividade para o município de Cabaceiras-PB. Revista Enciclopédia Biosfera, Centro Científico Conhecer - Goiânia, 11(21):2894.

Medeiros, RM. \& Santos, D. (2015). Balanço hídrico e erosividade em função das mudanças climáticas no Estado da Paraíba. Revista Brasileira de Geografia Física, 8(3):327-340.

Medeiros, RM.; Gomes Filho, MF. \& Costa Neto, FA.(2014). Erosividade da chuva na área da bacia hidrográfica do rio Uruçuí Preto- PI, Brasil visando o desenvolvimento de manejos do solo. $9^{\circ}$ congresso de educação agrícola superior Areia-PB - 27 a 30 de outubro de 2014. ISSN / 0101-756X.

Medeiros, RM.; Santos, DC.; Santos, DC. \& Rafaela, RA. (2014). Estimativa da erosividade da chuva em São João do Cariri- PB. $4^{\circ}$ Encontro Internacional da Governança da Água Governança da Água e Mudanças Climáticas.

Menezes, MD. \& Leite, FP. (2011). Avaliação e espacialização da erosividade da chuva no Vale do Rio Doce, região centro-leste de Minas Gerais. Revista Brasileira de Ciência do Solo, 34:1029-1039,

Needelman, BA. (2013). What are Soils?. Nature [online] 4.

Disponível:<http//:www.nature.com/scitable/knowledge/libnary/what-are-soils-67647639>.

Nunes, LH. (2016). Compreensões e ações frente aos padrões espaciais e temporais de riscos e desastres. Territorium, (16):179-189.

Oliveira, PT.; Silva, CMS. \& Lima, KC. (2014). Linear trend of occurrence and intensity of heavy rainfall events on Northeast Brazil. Atmospheric Science Letters, 135:598-617,

Oliveira JR., RC. (1996). Índice de erosividade das chuvas na região de Conceição do Araguaia, Pará. Belém: EMBRAPA-CPATU;. (Boletim de Pesquisa, nº 165). 
Peñalva-Bazzano, MG.; Eltz, FLF. \& Cassol, EA. (2010). Erosividade e características hidrológicas das chuvas de Rio Grande (RS). Revista Brasileira de Ciência do Solo, Viçosa, $34(1): 235-244$.

Pereira, AS.; Angelocci, LR. \& Sentelhas, PC. (2018). Metodologia da pesquisa científica. [ebook]. Santa Maria. Ed. UAB/NTE/UFSM. Acesso em: 5 maio 2020. Disponível em: https://repositorio.ufsm.br/bitstream/handle/1/15824/Lic_Computacao_MetodologiaPesquisa-Cientifica.pdf?sequence $=1$.

Pereira, APA.; Angelocci, LR \& Sentelhas, PC. (2012), Agrometeorologia: fundamentos e aplicações práticas. Guaiba - RS: Agropecuária, 478p.

Pires, FR. \& Souza, CM. (2013). Práticas mecânicas de conservação do solo e da água, 3 ed. Editora UFV, Viçosa.

Rosa, AG.; Sousa, AML.; Costa, JA. \& Souza, EB. (2016). Erosividade da chuva em Rondon do Pará, PA, Brasil de 1999 a 2015 e projetada para 2035. Rev. Ambient. Água. 11(4):10061021 ,

Santos, JA. (2007). Análise dos riscos ambientais relacionados às enchentes e deslizamentos na favela São José, João Pessoa - PB. 122p. Dissertação (Mestrado em Geografia). PPGG, Universidade Federal da Paraíba.

Santos, TEM. \& Montenegro, AAA. (2012). Erosividade e padrões hidrológicos de precipitação no Agreste Central pernambucano. Revista Brasileira de Engenharia Agrícola e Ambiental, Campina Grande 16(8):.871-880. 2012.

Schwab, GO.; fangmeier, DD.; Elliot, WJ. \& Frevert, RK. (1981). Soil and water conservation engineering. 3. ed. New York: John Wiley \& Sons.

Souza, EB.; Alves, JMB. \& Nobre, P. (1998). Anomalias de precipitação nos setores norte e leste do nordeste brasileiro em associação aos eventos do padrão de dipolo observados na bacia do atlântico tropical. Revista Brasileira de Meteorologia, 13(2), p.45-55. 
SUPERINTENDÊNCIA DE DESENVOLVIMENTO DO NORDESTE - SUDENE. (1990).

Dados Pluviométricos Mensais do Nordeste: Estado de Pernambuco. Recife. 363 p. (Série Pluviométrica).

Waltrick, PC. (2010). Erosividade de Chuvas do Paraná: atualização, influência do "El Niño" e "La Niña" e estimativa para cenários climáticos futuros. Dissertação (Mestrado em Ciência do Solo) - Universidade Federal do Paraná, Curitiba (PR), 107 p..

Wischmeier, WH.; Johnson, CB. \& Cross, BV. (1971). A soil erodibility nomograph for farmaland and construction sites. Journal of Soil and Water Conservation, Ankeny, 26:189193,

Wischmeier, WH. \& Smith, DD. (1978). Predicting rainfall erosion losses: a guide to conservation planning. Washington: USDA, 58p.

Wischmeier, WH. \& Smith, DD. (1958). Rainfall energy and its relationship to soil loss. Transactions of the American Geophysical Union, Washington, 39(2):285-291,

Yamamoto, JK. \& Landim, PMB. (2015). Conceitos e Aplicações. São Paulo: Oficina de textos,

Porcentagem de contribuição de cada autor no manuscrito

Manoel Vieira de França - 33,33

Raimundo Mainar de Medeiros - 33,33\%

Wagner Rodolfo de Araújo - 33,33\% 